\title{
Carbon retention by check dams: Regional scale estimation
}

\author{
Yihe Lü*, Ranhao Sun, Bojie Fu, Yafeng Wang \\ State Key Laboratory of Urban and Regional Ecology, Research Center for Eco-Environmental Sciences, Chinese Academy of Sciences, PO Box 2871, Beijing 100085, China
}

\section{A R T I C L E I N F O}

\section{Article history:}

Received 15 December 2011

Received in revised form 11 February 2012

Accepted 26 March 2012

Available online 2 May 2012

\section{Keywords:}

Check dam

Soil erosion

Carbon cycling

Sediment

Soil organic carbon

Loess Plateau

\begin{abstract}
A B S T R A C T
Check dams have been widely used globally as human introduced structures for watershed management for various purposes. However, the effects of these structures for carbon retention have been scarcely considered and quantified. This research formulated a simple approach in estimating the carbon retention effects of check dams in Yan'an prefecture of the Loess Plateau region of China based on check dam inventory data and benefit transfer approach. Results indicated that the large and medium sized check dams had retained about 42.3 million tons of soil organic carbon (SOC) with a high spatial variability. This is a significant amount similar to about $1.48 \%$ of the SOC stored in the $0-40 \mathrm{~cm}$ soil layer across the whole Loess Plateau or roughly $4 \%$ of the estimated carbon emission from fossil fuel in China in 2000 . Total volume of check dam is the most important influencing factor for carbon retention effects at both check dam and county-levels. Years after construction is also a significant factor at check dam level. The numbers of check dams and land use as well as topographical factors have impacts on the respect of check dam carbon retention of varied significance at the county-level. The effectiveness of carbon retention decreased from north to south. The results of this research can be used as important decision support for check dam development planning at the local context. This research also revealed the scientific worthiness in quantifying the carbon retention effects concerning the relationships between soil erosion and carbon cycling. On this respect, process-based monitoring and research are urgently in need.
\end{abstract}

(c) 2012 Elsevier B.V. All rights reserved.

\section{Introduction}

Global change under the impact of human activities poses threats to the life support systems for human survival including species and ecosystem services (Kerr et al., 2007). Carbon cycling, widely recognized as one of the key processes of the life support systems driving global environmental change, has already become a research frontier and hot spot in ecology, environmental and earth sciences (IPCC, 2007; Leemans et al., 2009; Schlesinger et al., 2011). Soil carbon is critical in carbon cycling because it accounts for about two thirds to three fourths terrestrial carbon pool, which is two times of the atmosphere carbon storage and three times of the vegetation carbon storage respectively (Smith et al., 2008). Therefore, a small change in the soil carbon pool may induce a significant change in the atmospheric carbon dioxide, which may have important implications on the global climate. Consequently, the status and dynamics of soil carbon pool is a key topic in carbon cycling research. Soil organic carbon (SOC) as an active component of the soil carbon pool has attained much importance in global change research.

\footnotetext{
* Corresponding author. Tel.: +86 10 62849102; fax: +86 1062849102.

E-mail address: lyh@rcees.ac.cn (Y. Lü).
}

Soil erosion may have profound impacts on soil carbon pool and carbon cycling. However, there are still intense debates on the role of soil erosion as a carbon source or sink for the global carbon cycle (Quine and van Oost, 2007; Harden et al., 2008; Kuhn et al., 2009). Therefore, it is important to understand the behaviors of SOC during soil erosion processes in eroded landscapes (Liu et al., 2003; Lal, 2005).

Soil erosion is also considered as a critical global environmental problem that affects the health of terrestrial ecosystems (Zuazo and Pleguezuelo, 2008; Shields et al., 2010). To mitigate the negative environmental impacts of soil erosion, a number of soil and water conservation measures have been adopted globally such as revegetation, tillage management, stone bunds, enclosures, terracing, and check dams (Valentin et al., 2005). Check dams are manmade hydrological engineering structures built across drainage channels (Zeng et al., 2009). Although usually constructed with objectives of soil erosion control, their functions can be multi-dimensional such as soil and water retention, ground water recharge, water harvesting and supply, gully and slope stabilization, control of debris flow, regulation of river channel morphology, improvement of habitat conditions for vegetation restoration (Heede, 1979; Balooni et al., 2008; deWolfe et al., 2008; Ran et al., 2008; Bombino et al., 2009; Hassanli et al., 2009; Garg et al., 2011). Hence, check dams are actually multi-functional landscape units. Furthermore, check dams can store significant proportion of the eroded soil carbon along with 
the effects of sediment retention and vegetation restoration (BoixFayos et al., 2009). This important effect of check dams on terrestrial carbon cycling, however, is short of study in the present scientific literature.

Check dams in the Loess Plateau of China have a long history of development because this region has suffered severe soil erosion with annual average soil loss of $5000-10,000$ tons per $\mathrm{km}^{2}$ (Fu et al., 2011). As one of the most efficient engineering approaches for sediment retention and high quality farmland development, check dams have been constructed in the Loess Plateau region for hundreds of years and the speed and magnitude of check dam development has been advanced in the last 50 years with the support of the Chinese government. Over 110 thousand check dams had been built, which had retained 700 million $\mathrm{m}^{3}$ of sediment and formed over three thousand $\mathrm{km}^{2}$ farmland by the end of 2002 (Xu et al., 2004). By the end of 2020, another 163 thousand check dams have been planned for construction, which can potentially trap 30 billion $\mathrm{m}^{3}$ of sediments and form over 50 thousand $\mathrm{km}^{2}$ farmland (Ran et al., 2005). The sediments trapped behind the check dams are transported from the surface soils of hill slopes and gullies by water erosion in the catchments controlled by the check dams. With the trapped sediments, a high proportion of the carbon from the original eroded soil is preserved accordingly (Thothong et al., 2011). The objectives of the present research are to: (1) formulate a simple method on estimating the carbon retention effects of check dams; (2) analyze the influencing factors and spatial differentiation of the carbon retention effects; (3) discuss the implications of check dams as functional landscape units for carbon retention.

\section{Materials and methods}

\subsection{Study area}

Yan'an prefecture was selected as the study area for this research. It locates in northern Shaanxi province in the middle reaches of the Yellow River and covers the central part of the Loess Plateau region (Fig. 1). Yan'an prefecture is composed of 13 county-level administrative units with a total land area of about 37 thousand $\mathrm{km}^{2}$ and a population of over two million. It is one of the most severe erosion sensitive areas with both loess hill ravine and loess mesa ravine topography (Xu et al., 2004). It has a continental semi-arid climate with annual average precipitation of $508 \mathrm{~mm}$ which mainly occurs during May and September as erosive rainfalls. The vegetation covers from the south to north are temperate forest, forest steppe, and steppe. Therefore, the bio-climate conditions are transitional in Yan'an prefecture. It is a hotspot for check dam development as major engineering measures for soil and water conservation. It accounts for about $6 \%$ of the total area of the loess plateau but the present and planned (2020) check dams in this region account for about $10 \%$ and $17 \%$ of the total number of check dams, respectively.

\subsection{Data source}

The check dam survey dataset was collected from the Bureau of Water Resources of Yan'an prefecture. This dataset include detailed information on medium and large scale check dams up to the end of 2009. The information was composed of the geographic locations and administrative affiliations of check dams, names of check dams, the controlled watershed land area, time of construct completion, the total volume and silted volume as well as the height of check dams. The use and management conditions of check dams were also recorded. County-level population data were collected from Statistic Bureau of Yan'an prefecture Government. Topographic data at a resolution of 1:250,000 were from National Geomatics Center of China (http://ngcc.sbsm.gov.cn/Guide/). Land use/land cover data of 2008 was derived from China-Brazil Earth Resources Satellite (CBERS-2b) images with a $20 \mathrm{~m}$ ground resolution. Population and land use data were used to identify the influencing factors of carbon retention by check dams at county-level.

\subsection{Carbon retention estimation and correlation analysis}

The carbon retention effects of the medium and large scale check dams in county-level administrative regions were estimated using the following equation.

$\mathrm{SOC}_{i}=\mathrm{BD} \times \mathrm{CC} \times \sum_{j=1}^{n} \mathrm{SD}_{i j}$

where SOC is the amount of soil organic carbon stored in the sediments deposited behind the check dam (t); SD represents the volume of sediment deposited $\left(\mathrm{m}^{3}\right)$; BD denotes the average bulk density of the sediments $\left(\mathrm{t} \mathrm{m}^{-3}\right)$; $\mathrm{CC}$ is the average content of soil organic carbon in the deposited sediments (\%); $i$ and $j$ represent the $i$ th region and the $j$ th check dam in the region, respectively.

In the above equation, the SD was already known in the check dam dataset. The other two parameters need to be quantified using data synthesized from published scientific papers concerning similar regions, which is also known as the benefit transfer approach usually used in regional and global scale ecosystem service research (Wilson and Hoehn, 2006).

Four research articles were found reporting the quantitative analysis on the bulk densities of the sediment deposited behind check dams in northern Shaanxi province (Table 1). This study chose the average level of the reported sediment bulk density of $1.38\left(\mathrm{~g} / \mathrm{cm}^{3}=\mathrm{t} / \mathrm{m}^{3}\right)$ as the value for parameter BD in Eq. (1).

Most of the studies on soil carbon behind check dams (dam land) were found to use soil organic matter (SOM) as the indicator. SOM was converted to SOC using a factor of 0.58 , and the results are shown in Table 2. This study chose the median of the mean value of the SOC content $(0.43 \%)$ in the deposited sediments of check dams.

Considering the effectiveness of carbon retention by check dams at county-level, this paper formulated a dimensionless integrative carbon retention effectiveness index (ICREI) based on carbon retention amount (CRA), carbon retention intensity (CRI), and mean carbon retention capacity (MCRC). Firstly, the row vectors of CRA, CRI, and MCRC (Table 3) were standardized using the function of $X_{i}=\left[x_{i j}-\min \left(x_{i j}\right)\right] /\left[\max \left(x_{i j}\right)-\max \left(x_{i j}\right)\right] . x_{i j}$ denotes the $j$ th value of row vectors of CRA, CRI, and MCRC. $j$ is the $j$ th county. $X_{1}, X_{2}$, and $X_{3}$ represent the standardized row vector of CRA, CRI, and MCRC, respectively. Then we have $\operatorname{ICREI}_{j}=\sum_{i} w_{i} * X_{i}(i=1,2,3 ; j=1$ to $13, \mathrm{j} \in \mathrm{N})$. Set $w=(0.4,0.3,0.3)$. CRA is the amount of SOC retained by check dams estimated from Eq. (1); CRI is the amount of carbon retention (CRA) divided by the watershed areas controlled by the check dams; MCRC is the average carbon retention amount per check dam.

Correlation analysis between check dam carbon retention and the potential influencing factors were processed using MATLAB at check dam and county-level. At the single check dam level, correlations were detected between the amounts of carbon retention by check dams and the quantitative attributes including the height, total volume, years after construction complete of check dams as well as the watershed areas controlled by check dams. At the county-level, more variables including land uses and topographic characteristics were incorporated in correlation analysis with the amount, intensity (total carbon retention amount/total controlled 


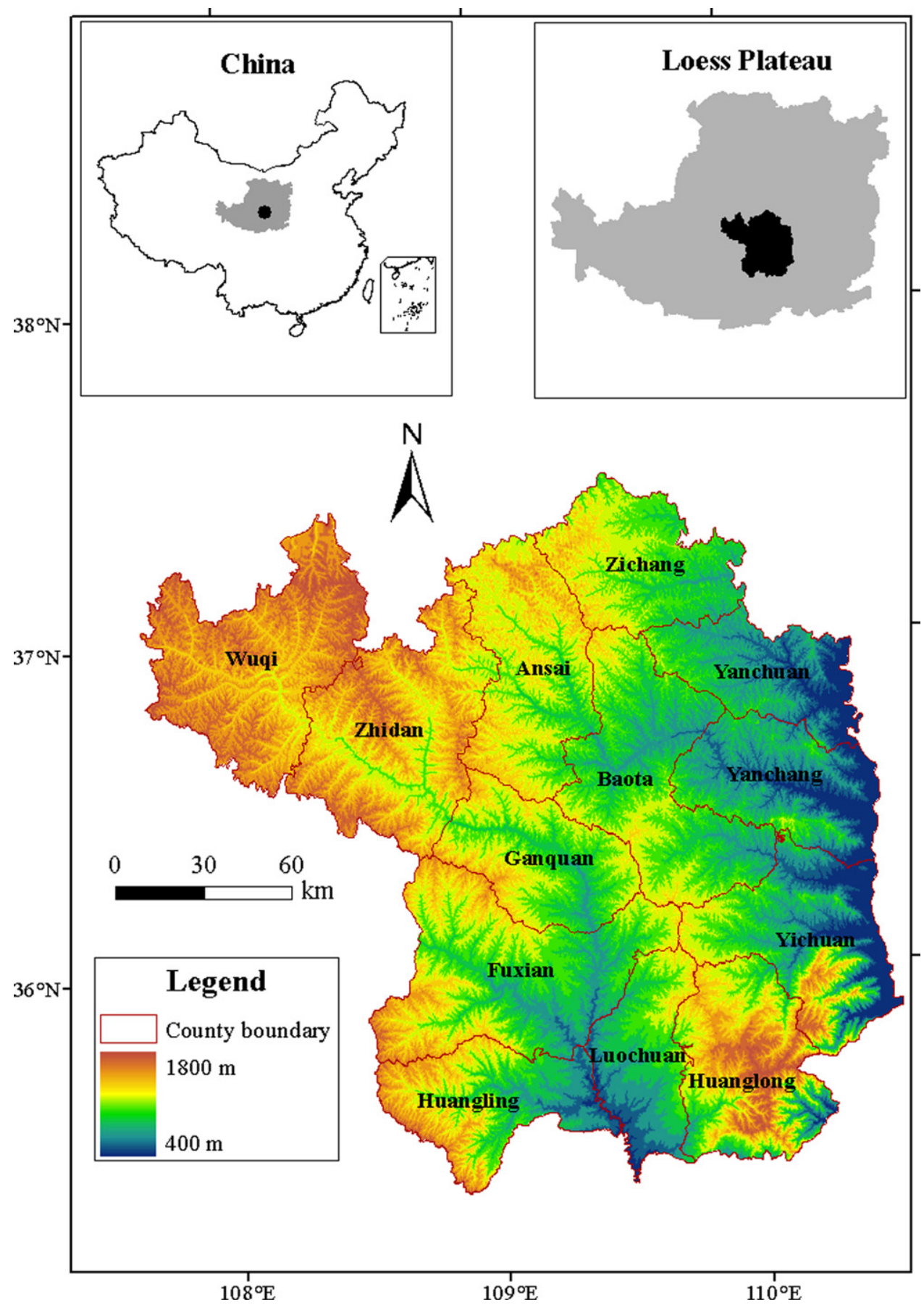

Fig. 1. The location, county-level areas, and topography of Yan'an prefecture.

Table 1

The reported bulk densities of sediments trapped by check dams.

\begin{tabular}{|c|c|c|c|c|c|}
\hline No. & Sample size & Sampling depth (m) & Mean bulk density $\left(\mathrm{g} / \mathrm{cm}^{3}\right)$ & Standard deviation & Source \\
\hline 1 & 11 & Not reported & 1.38 & 0.03 & Sun et al. (2004) \\
\hline 2 & 10 & 6.3 & 1.37 & 0.07 & Wei et al. (2006) \\
\hline 3 & 7 & 6.6 & 1.32 & 0.07 & Li et al. (2007) \\
\hline 4 & 69 & 5.5 & 1.45 & 0.12 & Wang et al. (2008) \\
\hline
\end{tabular}


Table 2

The reported soil organic carbon in sediments trapped by check dams.

\begin{tabular}{|c|c|c|c|c|c|}
\hline No. & Sample size & Sampling depth (m) & SOC (\%) & Standard deviation & Source \\
\hline 1 & 41 & 1.0 & 0.32 & 0.09 & Bi et al. (1997) \\
\hline 2 & 7 & 0.2 & 0.58 & 0.07 & Zhang et al. (1999) \\
\hline 3 & 41 & Not reported & 0.63 & 0.36 & $\mathrm{Li}$ and Bai (2003) \\
\hline 4 & 16 & 2.0 & 0.29 & 0.01 & Bao et al. (2005) \\
\hline 5 & 7 & 0.2 & 0.43 & 0.04 & Wang et al. (2007) \\
\hline 6 & 44 & 0.6 & 0.32 & 0.07 & Bao et al. (2008) \\
\hline 7 & 18 & 1.0 & 0.45 & 0.17 & Sun and Guo (2011) \\
\hline
\end{tabular}

Table 3

Carbon retention by check dams at county level.

\begin{tabular}{|c|c|c|c|c|c|c|c|c|c|c|c|c|c|}
\hline & AS & BT & FX & GQ & HL & $\mathrm{Hl}$ & LC & WQ & YC & Yc & yc & ZD & $\mathrm{ZC}$ \\
\hline Check dam No. & 281 & 402 & 23 & 34 & 4 & 3 & 4 & 214 & 322 & 192 & 12 & 230 & 626 \\
\hline CRA $\left(10^{4} t\right)$ & 507.2 & 458.4 & 3.5 & 2.5 & 4.3 & 2.4 & 2.7 & 706.5 & 503.6 & 314.7 & 5.0 & 377.4 & 1337.7 \\
\hline CRI $\left(10^{3} \mathrm{t} / \mathrm{km}^{2}\right)$ & 3.86 & 4.14 & 0.24 & 0.12 & 0.98 & 0.74 & 1.49 & 8.96 & 1.63 & 9.19 & 1.48 & 6.27 & 9.66 \\
\hline $\operatorname{MCRC}\left(10^{4} \mathrm{t}\right)$ & 1.80 & 1.14 & 0.15 & 0.07 & 1.08 & 0.80 & 0.68 & 3.30 & 1.56 & 1.64 & 0.42 & 1.64 & 2.14 \\
\hline
\end{tabular}

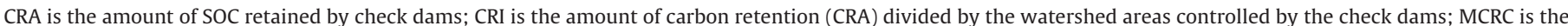

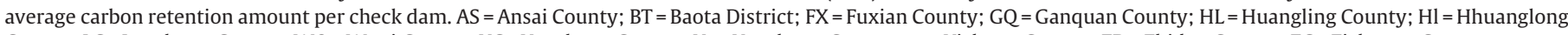
County; LC=Luochuan County; WQ=Wuqi County; YC= Yanchang County; Yc= Yanchuan County; yc= Yichuan County; ZD = Zhidan County; ZC=Zichuang County.

watershed area), and capacity (total carbon retention amount/total number of check dams) of carbon retention by check dams.

\section{Results}

\subsection{Carbon retention by check dams at county-level}

There were 2347 large and medium scaled check dams in the 13 county-level administrative areas. These check dams controlled $9110.8 \mathrm{~km}^{2}$ of watersheds, which covered $24.8 \%$ of the total land surface in Yan'an prefecture. The estimated amount of carbon retention by these check dams equaled to be about 42.3 million tons.

There were seven county-level administrative areas where the amounts of carbon retention by check dams were above three million tons (Table 1). Zichang County was the highest in the number of medium and large scaled check dams as well as the intensity and amount of carbon retained by these check dams. Wuqi County ranked the second on carbon retention amount and the third on carbon retention intensity but the highest per dam carbon retention capacity with only the sixth on the total number of check dams inventoried. Yanchuan County ranked the second, fourth on check dam carbon retention intensity and mean capacity with the seventh of the amount of carbon retention and the number of check dams. Baota District ranked the second on the number of check dams, the fourth on carbon retention intensity, the fifth on carbon retention amount, and the seventh on mean carbon retention capacity. Ansai County ranked the third on carbon retention quantity, the fourth on the number of check dams, the sixth on carbon retention intensity and capacity. Yanchang County had higher number of check dams and carbon retained than Zhidan County, which was just contrary to their rankings on the other two indicators of check dam carbon retention intensity and capacity. The remaining six counties felled far behind on both the number of check dams and carbon retention characteristics.

Spatially, carbon retention intensities were high in the northern six counties followed by the southern and southeastern five counties, and the southwestern two counties were lowest in carbon retention intensities by check dams (Fig. 2). The spatial pattern of mean carbon retention capacity differed from that of carbon retention intensities (Fig. 3). The northern and northeastern six counties showed the highest carbon retention capacities by check dams, while, the south-central three counties were the lowest on carbon retention capacities.

The results of ICREI were shown with ascending order in Fig. 4. It is clear that Zichang county and Wuqi county were the highest in check dam carbon retention effectiveness. However, Ganquan county and Fuxian County were the least effective. Spatially, the effectiveness is the highest in the north and northwest and decreases to the north central, southeast, south, and finally the west-central. This ranking and spatial pattern of county-level administrative areas can be used as important input for spatially explicit planning of new check dams at county-level (Fig. 5).

\subsection{The interrelationships between carbon retention and other factors}

At the check dam level, the check dams were divided into two size groups for correlation analysis (Table 4). For the medium check dams, carbon retention amounts were significantly correlated with all the four check dam properties including the watershed areas controlled, dam height, dam total volume, and the years after construction. For the large check dams, carbon retention amounts correlated only significantly to total dam volume and years after construction. The correlation coefficients were the biggest between carbon retention amounts and total dam volumes. The correlation coefficients between carbon retention amount and controlled watershed area and years after construction ranked the second, respectively, for medium and large check dams.

Carbon retention amounts, intensities, and mean capacities were detected to be positively correlated to the number and total volume of check dams as well as the grassland area fraction but correlated negatively with forestland fraction at the county-level (Table 5). These correlations were statistically significant at least at $P<0.05$ level. Only carbon retention amounts exhibited a statistically positive correlation with the controlled watershed areas by check dams at county-level. Carbon retention characteristics were generally negatively correlated to topographic variables including gully density and mean slope gradient at the county-level, within which the correlations between carbon retention amount and topographical variables were not statistically significant. The carbon retention characteristics correlated positively to road density and tested as statistically significant except for the correlation between carbon retention capacity and road density. 


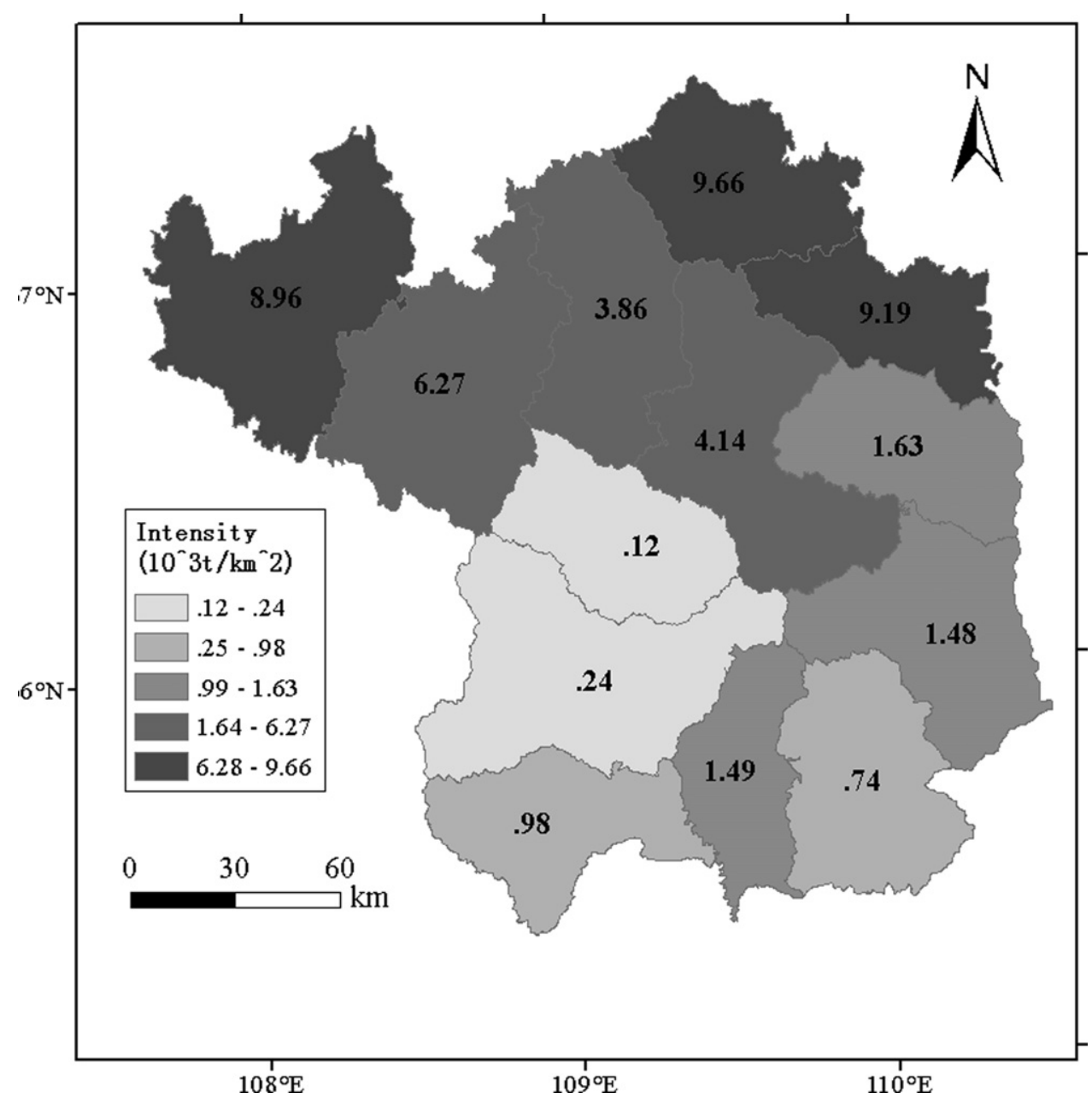

Fig. 2. The spatial pattern of carbon retention intensity by check dams at county-level.

\section{Discussions}

\subsection{The influencing factors and effectiveness of carbon retention by check dams}

From correlation analysis, it is clear that the total volume of check dams is the most important factor for carbon retention by check dams at both the check dam and county-level. The carbon retention by medium scaled check dams is sensitive to all the four factors at different degrees including controlled watershed area, dam height, total dam volume, and years after construction. The importance of the four factors can be ranked as total dam volume $>$ controlled watershed area $>$ dam height $>$ years after construction. However, only total dam volume and years after construction remained to be significant influencing factors for large check dams on carbon retention. As to the carbon retention amount by check dams at county-level, three dam properties (total dam volume, number of check dams, and controlled watershed area) and three land use characteristics (grassland fraction, road density, and forestland fraction) tended to have significant influences. Road provide accessibility to gullies and high grassland fraction implied high vulnerability to soil erosion (Wang et al., 2006; Fang et al., 2011). Therefore, these two factors contributed positively to carbon retention amount in check dams. However, high fraction of forestland notifies more stable and erosion resistant environment on hillslopes that contribute negatively to carbon retention by check dams (Wang et al., 2011). To carbon retention intensity and mean carbon retention capacity, controlled watershed area became a non-significant factor, while, the two topographic attributes including gully density and mean slope gradient became significant negative influencing factors. This is possibly because high gully density and steep hillslopes can make it unsuitable for sitting check dams (Nyssen et al., 2004; Pandey et al., 2011). There may be some correlations between the factors influencing carbon retention by check dams (e.g., the total number and volume of check dams at county level). In spite of this, the focus of the present research on correlation analysis, which is to find the potential influencing factors and their relative importance have been addressed at both check dam and county levels (Tables 4 and 5).

\subsection{Carbon retention enhancing the multi-functionality of check dams}

Traditionally, check dams were built in the Loess Plateau region as an important engineering measure primarily for soil erosion control (Xu et al., 2004). The check dams can form ponds or reservoirs for aquaculture (Yin and $\mathrm{Xu}, 2006$ ). After silting up, high quality croplands can be reclaimed for growing food or cash crops. Therefore, the effectiveness of check dams as engineering approach for erosion control and agricultural development considered mainly the functions of check dams on sediment trapping, water supply, areas of cropland formed, and revenues from agricultural production (Zhang, 2007) at watershed or regional scale. The present research indicated that check dams also had significant function of carbon retention especially at regional scale. Another 


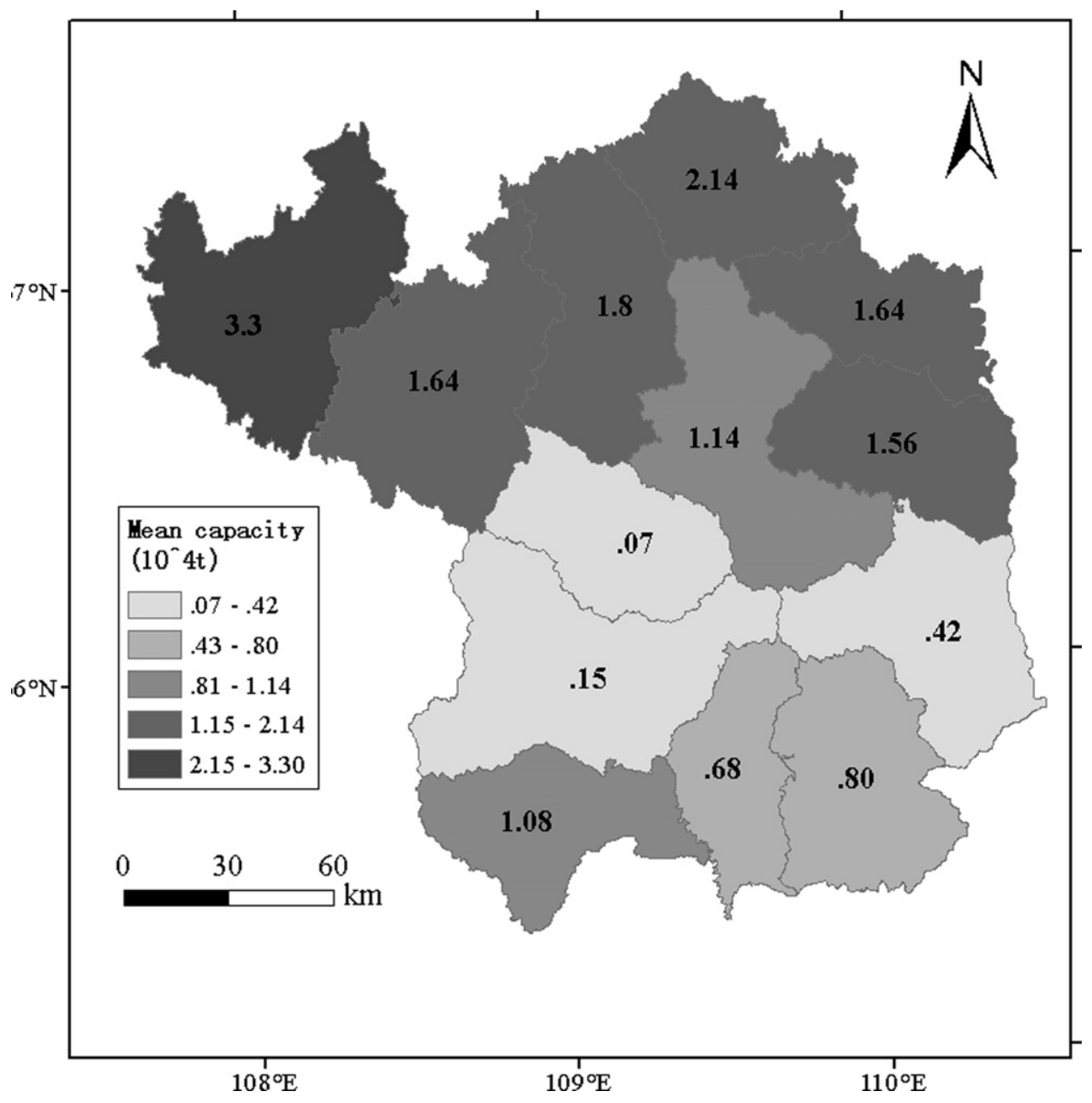

Fig. 3. The spatial pattern of mean carbon retention capacity by check dams at county-level.

10,135 small check dams in Yan'an prefecture by the end of 2009 were not included in our carbon retention estimation because only the numbers of small check dams grouped according to watersheds and counties were available in the dataset. Therefore, this research only gave partial estimation or underestimation of the carbon retention effects by check dams in Yan'an prefecture. Even though, the estimated amount of carbon retention by large and medium check dams in Yan'an prefecture accounted for about $1.48 \%$ of the SOC stored in the $0-40 \mathrm{~cm}$ soil layer across the whole Loess Plateau region (Liu et al., 2011), or roughly $4 \%$ of the estimated carbon emission from fossil fuel in China in 2000 (Lal, 2004). Therefore, check dams are actually multifunctional landscape

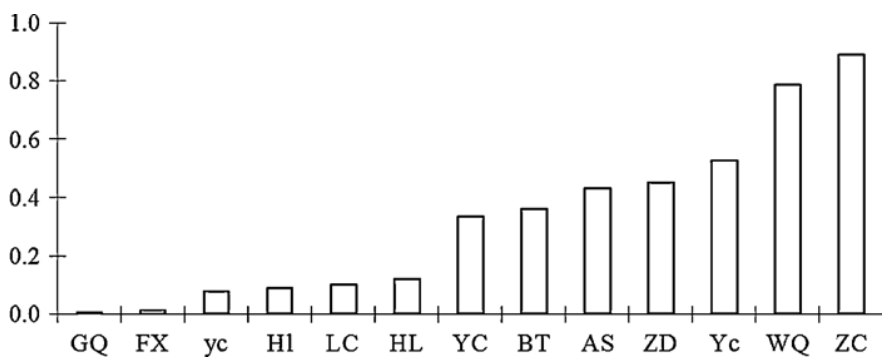

Fig. 4. The integrative effectiveness of carbon retention by check dams at countylevel. $\mathrm{AS}=$ Ansai County; BT = Baota District; FX=Fuxian County; GQ=Ganquan County; $\mathrm{HL}=$ Huangling County; $\mathrm{Hl}=$ Hhuanglong County; LC=Luochuan County; $\mathrm{WQ}=$ Wuqi County; YC=Yanchang County; Yc=Yanchuan County; yc=Yichuan County; ZD = Zhidan County; ZC = Zichuang County. units that can also trap huge amount of carbon in sediments. They have been used globally across various climate conditions such as the semiarid west Asia and Mediterranean region as well as humid European mountains (Wohl, 2006; Castillo et al., 2007; Hassanli et al., 2009). The carbon retention effects of these units cannot be neglected both for functional appraisal on check dams and their potential impacts on carbon cycling. Check dams retain carbon to avoid carbon release to larger channels and the possible emission to atmosphere during transport process in water. At the same time, new carbon input to soil from plants on hillslopes to compensate the carbon loss during soil erosion (Yoo et al., 2005; Berhe et al., 2008). Therefore, check dams can contribute to carbon sequestration at watershed and regional scales that may have important implications for global change. Hence, the quantification of check dams on carbon retention is necessary to improve the scientific understanding on the relationships between soil erosion-deposition process and carbon cycling as well as human intervention effects on this relationship, which will be insightful for carbon modeling from watershed to global scale. For newly built or un-filled check dams, the volume of sediment deposited (SD) will increase with time. Therefore, the quantification of carbon retention by check dams needs to incorporate the time dimension. In this sense, the present assessment can be treated as a snap shot at the end of 2009. Actually, both space and time are important in analyzing soil carbon dynamics (Dean et al., 2012). Therefore, both ecological monitoring and spatiotemporal modeling are needed for carbon retention research (Verhoeven, 2010). 


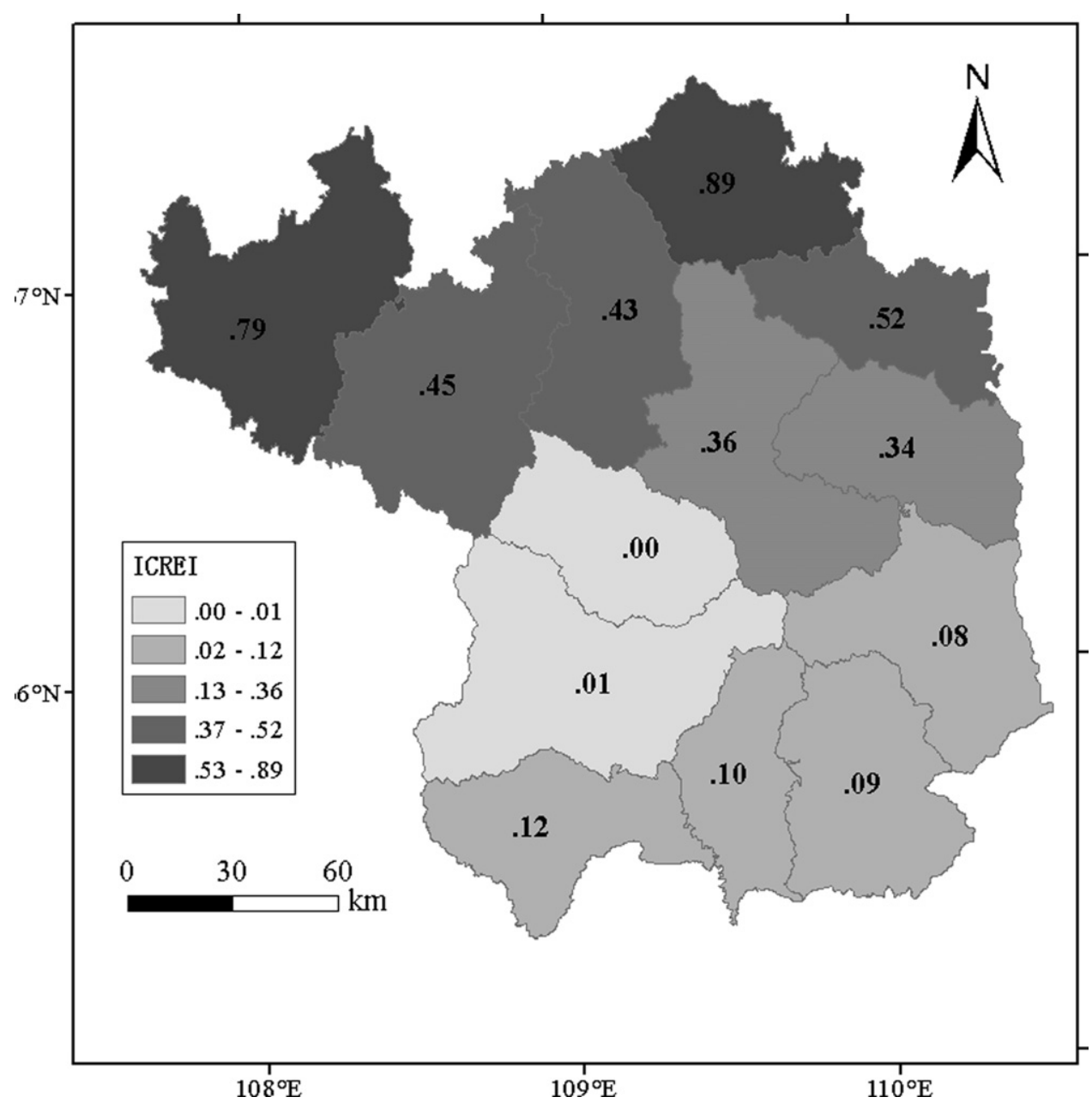

Fig. 5. The spatial pattern of integrative check dam carbon retention effectiveness at county-level.

Table 4

Check dam level correlation between carbon retention and dam attributes.

\begin{tabular}{|c|c|c|c|c|c|}
\hline Correlation & & Controlled watershed area & Dam height & Total dam volume & Years after construction \\
\hline Carbon retention & Medium check dams & $0.6356^{\mathrm{a}}$ & $0.3375^{\mathrm{a}}$ & $0.8945^{\mathrm{a}}$ & $0.1517^{a}$ \\
\hline amount & Large check dams & 0.0534 & 0.0534 & $0.6115^{a}$ & $0.5179^{a}$ \\
\hline
\end{tabular}

a $P<0.0001$

Table 5

Correlations between carbon retention and other factors at county level.

\begin{tabular}{|c|c|c|c|c|c|c|c|c|}
\hline Correlation coefficients & $\begin{array}{l}\text { Check dam } \\
\text { No. }\end{array}$ & $\begin{array}{l}\text { Controlled } \\
\text { watershed area }\end{array}$ & $\begin{array}{l}\text { Total } \\
\text { volume }\end{array}$ & $\begin{array}{l}\text { Gully } \\
\text { density }\end{array}$ & $\begin{array}{l}\text { Mean slope } \\
\text { gradient }\end{array}$ & $\begin{array}{l}\text { Road } \\
\text { density }\end{array}$ & $\begin{array}{l}\text { Forestland } \\
\text { ratio }\end{array}$ & $\begin{array}{l}\text { Grassland } \\
\text { ratio }\end{array}$ \\
\hline Carbon retention amount (CRA) & $0.938^{\mathrm{a}}$ & $0.606^{c}$ & $0.972^{\mathrm{a}}$ & -0.382 & -0.408 & $0.601^{c}$ & $-0.526^{c}$ & $0.604^{c}$ \\
\hline $\begin{array}{l}\text { Carbon retention intensity } \\
(\text { CRI })\end{array}$ & $0.680^{c}$ & 0.215 & $0.771^{\mathrm{b}}$ & $-0.536^{c}$ & $-0.542^{c}$ & $0.567^{c}$ & $-0.618^{c}$ & $0.579^{c}$ \\
\hline $\begin{array}{l}\text { Mean carbon retention } \\
\text { capacity (MCRC) }\end{array}$ & $0.607^{c}$ & 0.447 & $0.767^{\mathrm{b}}$ & $-0.649^{c}$ & $-0.602^{c}$ & 0.4874 & $-0.533^{c}$ & $0.597^{c}$ \\
\hline
\end{tabular}

$$
\text { a } P<0.001 \text {. }
$$

b $P<0.01$.

c $P<0.05$.

\section{Conclusion}

Because check dams are widely used at the global scale with multiple purposes such as sediment and soil erosion control, water supply and regulation, groundwater recharge, and agricultural production, they are actually human introduced multifunctional landscape units. In this paper, we formulated a simple approach to estimate the effects of carbon retention by check dams at regional scale on the basis of check dam inventory data and benefit transfer on soil bulk density and soil organic carbon content. Significant effects of carbon retention by check dams were found to be existed with high level of spatial variability. The carbon retention effects of check dams are parallel and synergistic to their effects on sediment trapping during soil erosion and sediment transport processes, which have been largely neglected. The present estimation proved that check dams can significantly contribute to carbon 
sequestration at watershed to global scales. This effect can be influenced by many factors in space and time. Therefore, we recommend further in-depth analysis on the underlying processes that determining check dam carbon retention effects and their contribution to regional carbon cycling as well as the implications on global carbon budget.

\section{Acknowledgements}

This research was supported by the Chinese Academy of Sciences (KZCX2-YW-QN408), the National Key Basic Research Program (2009CB421104), and the National Natural Science Foundation of China (41171156).

\section{References}

Balooni, K., Kalro, A.H., Kamalamma, A.G., 2008. Community initiatives in building and managing temporary check-dams across seasonal streams for water harvesting in South India. Agric. Water Manage. 95, 1314-1322.

Bao, Y.X., Wu, F.Q., Tan, H.C., 2005. Distribution characteristics of soil nutrients in Dam Land. B. Soil Water Conserv. 25 (2), 12-15 (in Chinese with English Abstract).

Bao, Y.X., Wu, F.Q., Jia, Y.K., 2008. Characteristics and evolution of soil nitrogen in dam land and terrace in Loess Hilly region. J. Northwest Agric. Forestry Univ. (Nat. Sci. Ed.) 36 (3), 97-104 (in Chinese with English Abstract)

Berhe, A.A., Harden, J.W., Torn, M.S., Harte, J., 2008. Linking soil organic matter dynamics and erosion-induced terrestrial. J. Geophys. Res. 113, G04039, http://dx.doi.org/10.1029/2008JG000751.

Bi, Y.L., Wang, B.Q., Guo, S.L., Yu, C.Z., 1997. Characteristic of soil nutrients in dam system and its relation with erosive environment in the Loess Hilly region. J. Soil Erosion Soil Water Conserv. 3 (3), 1-9 (in Chinese with English Abstract).

Boix-Fayos, C., de Vente, J., Albaladejo, J., Martínez-Mena, M., 2009. Soil carbon erosion and stock as affected by land use changes at the catchment scale in Mediterranean ecosystems. Agr. Ecosyst. Environ. 133, 75-85.

Bombino, G., Gurnell, A.M., Tamburino, V., Zema1, D.A., Zimbone, S.M., 2009. Adjustments in channel form, sediment calibre and vegetation around check-dams in the headwater reaches of mountain torrents Calabria, Italy. Earth Surf. Proc. Land. 34, 1011-1021.

Castillo, V.M., Mosch, W.M., Conesa Garcí, C., Barberá, G.G., Navarro Cano, J.A., LópezBermúdez, F., 2007. Effectiveness and geomorphological impacts of check dams for soil erosion control in a semiarid Mediterranean catchment: El Cárcavo (Murcia, Spain). Catena 70, 416-427.

Dean, C., Roxburgh, S.H., Harper, R.J., Eldridge, D.J., Watson, I.W., Wardell-Johnson, G.W., 2012. Accounting for space and time in soil carbon dynamics in timbered rangelands. Ecol. Eng. 38, 51-64.

deWolfe, V.G., Santi, P.M., Ey, J., Gartner, J.E., 2008. Effective mitigation of debris flows at Lemon Dam, La Plata County, Colorado. Geomorphology 96, 366-377.

Fang, H.Y., Li, Q.Y., Cai, Q.G., 2011. A study on the vegetation recovery and crop pattern adjustment on the Loess Plateau of China. Afr. J. Microbiol. Res. 5 1414-1419.

Fu, B.J., Liu, Y., Lu, Y.H., He, C.S., Zeng, Y., Wu, B.F., 2011. Assessing the soil erosion control service of ecosystems change in the Loess Plateau of China. Ecol. Complex. 8, 284-293.

Garg, K.K., Karlberg, L., Barron, J., Wani1, S.P., Rockstrom, J., 2011. Assessing impacts of agricultural water interventions in the Kothapally watershed, Southern India. Hydrol. Process., http://dx.doi.org/10.1002/hyp.8138.

Harden, J.W., Berhe, A.A., Torn, M., Harte, J., Liu, S., Stallard, R.F., 2008. Soil erosion: data say C sink. Science 320, 178-179.

Hassanli, A.M., Nameghi, A.E., Beecham, S., 2009. Evaluation of the effect of porous check dam location on fine sediment retention (a case study). Environ. Monit. Assess. 152, 319-326.

Heede, B.H., 1979. Deteriorated watershed can be restored: a case study. Environ. Manage. 3, 271-281.

IPCC, 2007. Climate Change 2007: Synthesis Report. [Core Writing Team, Pachauri, R.K., Reisinger, A. (eds.)]. IPCC, Geneva, Switzerland, 104 pp.

Kerr, J.T., Kharouba, H.M., Currie, D.J., 2007. The macroecological contribution to global change solutions. Science 316, 1581-1584.

Kuhn, J.T., Hoffmann, T., Schwanghart, W., Dotterweich, M., 2009. Agricultural soil erosion and global carbon cycle: controversy over? Earth Surf. Proc. Land 34, 1033-1038.

Lal, R., 2004. Offsetting China's $\mathrm{CO}_{2}$ emissions by soil carbon sequestfractionn. Climatic Change 65, 263-275.

Lal, R., 2005. Soil erosion and carbon dynamics. Soil Till. Res. 81, 137-142.

Leemans, R., Asrar, G., Busalacchi, A., Canadell, J., Ingram, J., Larigauderie, A., Mooney, H., Nobre, C., Patwardhan, A., Rice, M., Schmidt, F., Seitzinger, S., Virji, H., Vorosmarty, C., Young, O., 2009. Developing a common strategy for integrative global environmental change research and outreach: the Earth System Science Partnership (ESSP) Strategy paper. Curr. Opin. Environ. Sust. 1, 4-13.
Li, Y., Bai, L.Y., 2003. Variations of sediment and organic carbon storage by checkdams of Chinese Loess Plateau. J. Soil Water Conserv. 17 (2), 1-4 (in Chinese with English Abstract).

Li, X.G., Li, Z.B., Wei, X., 2007. Two key physical characteristics indexes of farmland sediment for check dams in Loess Plateau. Res. Soil Water Conserv. 14, 218-220 (in Chinese with English Abstract).

Liu, S.G., Bliss, N., Sundquist, E., Huntington, T.G., 2003. Modeling carbon dynamics in vegetation and soil under the impact of soil erosion and deposition. Global Biogeochem. Cycles 17 (2), 1074, http://dx.doi.org/10.1029/2002GB002010.

Liu, Z.P., Shao, M.A., Wang, Y.Q., 2011. Effect of environmental factors on regional soil organic carbon stocks across the Loess Plateau region. China. Agr. Ecosyst. Environ. 142, 184-194.

Nyssen, J., Veyret-Picot, M., Poesen, J., Moeyersons, J., Haile, M., Deckers, J., Govers, G., 2004. The effectiveness of loose rock check dams for gully control in Tigray, northern Ethiopia. Soil Use Manag. 20, 55-64.

Pandey, A., Chowdary, V.M., Mal, B.C., Dabral, P.P., 2011. Remote sensing and GIS for identification of suitable sites for soil and water conservation structures. Land Degrad. Dev. 22, 359-372.

Quine, T.A., van Oost, K., 2007. Quantifying carbon sequestration as a result of soil erosion and deposition: retrospective assessment using caesium-137 and carbon inventories. Global Change Biol. 13, 2610-2625.

Ran, D.C., Wang, Z.G., Hu, J.J., Ma, Y., Pang, X.M., 2005. Construction scale and demonstration of silt-arresting dams depending on grain demands in the Loess Plateau. Agr. Res. Arid Areas 23 (3), 130-136 (in Chinese with English abstract).

Ran, D.C., Luo, Q.H., Zhou, Z.H., Wang, G.Q., Zhang, X.H., 2008. Sediment retention by check dams in the Hekouzhen-Longmen section of the Yellow River. Int. J. Sediment Res. 23, 159-166.

Schlesinger, W.H., Cole, J.J., Finzi, A.C., Holland, E.A., 2011. Introduction to coupled biogeochemical cycles. Front. Ecol. Environ. 9, 5-8.

Shields, F.D., Lizotte, R.E., Knight, S.S., Cooper, C.M., Wilcox, D., 2010. The stream channel incision syndrome and water quality. Ecol. Eng. 36, 78-90.

Smith, P., Fang, C.M., Dawson, J.J.C., Moncrieff, J.B., 2008. Impact of global warming on soil organic carbon. Adv. Agron. 97, 1-43.

Sun, W.Y., Guo, S.L., 2011. The spatial distribution of soil organic carbon and it's influencing factors in hilly region of the Loess Plateau. Acta Ecol. Sin. 31, 1604-1616.

Sun, Q.L., Wang, H.X., Ma, J.Q., 2004. Estimating soil erosion status on hill slopes based on the survey of sediment deposition behind check dams. Soil Water Conserv. Sci. Techn. Shanxi 30 (1), 28-30 (in Chinese).

Thothong, W., Huon, S., Janeau, J.L., Boonsaner, A., de Rouw, A., Planchon, O., Bardoux, G., Parkpian, P., 2011. Impact of land use change and rainfall on sediment and carbon accumulation in a water reservoir of North Thailand. Agr. Ecosyst. Environ. 140, 521-533.

Valentin, C., Poesen, J., Li, Y., 2005. Gully erosion: impacts, factors and control. Catena 63, 132-153.

Verhoeven, J.T.A., 2010. Carbon, nutrient and metal retention in wetlands in a restoration context. Ecol. Eng. 36, 611.

Wang, E., Xin, C., Williams, J.R., Xu, C., 2006. Predicting soil erosion for alternative land uses. J. Environ. Qual. 35, 459-467.

Wang, X.L., Guo, S.L., Ma, Y.H., Huang, D.Y., Wu, J.S., 2007. Effects of land use type on soil organic $\mathrm{C}$ and total $\mathrm{N}$ in a small watershed in loess hilly-gully region. Chinese J. App. Ecol. 18, 1281-1285 (In Chinese with English Abstract).

Wang, Y.Q., Zhang, X.C., Han, F.P., 2008. Profile variability of soil properties in check dam on the Loess Plateau and its functions. Environ. Sci. 29, 1020-1026 (in Chinese with English Abstract).

Wang, Y.F., Fu, B.J., Lu, Y.H., Chen, L.D., 2011. Effects of vegetation restoration on soil organic carbon sequestration at multiple scales in semi-arid Loess Plateau, China. Catena 85, 58-66.

Wei, X., Li, Z.B., Li, X.G., Lu, K.X., 2006. Distribution law of deposits' dry bulk density and its application in sediment restoration of check-dam. J. Northwest Sci. Tech. Univ. Agri. Forestry (Nat. Sci. Ed.) 34 (10), 192-196 (in Chinese with English Abstract).

Wilson, M.A., Hoehn, J.P., 2006. Valuing environmental goods and services using benefit transfer: the state-of-the art and science. Ecol. Econ. 60, 335-342.

Wohl, E., 2006. Human impacts to mountain streams. Geomorphology 79, 217 248.

Xu, X.Z., Zhang, H.W., Zhang, O., 2004. Development of check-dam systems in gullies on the Loess Plateau. China. Environ. Sci. Policy 7, 79-86.

Yin, H.M., Xu, S.L., 2006. The status and policy recommendations on check dam aquaculture development in west mountain areas of Linfen prefecture. Shanxi Water Resources 27 (6), 121-122 (in Chinese)

Yoo, K., Amundson, R., Heimsath, A.M., Dietrich, W.E., 2005. Erosion of upland hillslope soil organic carbon: coupling field measurements with a sediment transport model. Global Biogeochem. Cycles 19, GB3003, http://dx.doi.org/10.1029/2004GB002271.

Zeng, Q.L., Yue, Z.Q., Yang, F., Zhang, X.J., 2009. A case study of long-term field performance of check-dams in mitigation of soil erosion in Jiangjia stream. China. Environ. Geol. 58, 897-911.

Zhang, H.X., 2007. The functions of silt arresters on water and soil conservation form dam construction in a river valley-taking Yuanhe River valley in Haiyuan of Ningxia as an example. J. Agr. Sci. 28 (4), 51-54.

Zhang, C.E., Wang, S.Q., Deng, X.P., 1999. Primary fertility and approaches of improving fertility in Yaner Gully watershed of North Yan'an area. Bull. Soil Water Conserv. 19 (5), 15-20 (in Chinese with English Abstract).

Zuazo, V.H.D., Pleguezuelo, C.R.R., 2008. Soil-erosion and runoff prevention by plant covers: a review. Agron. Sustain. Dev. 28, 65-86. 